\title{
Changes in the Long-term Prognosis of Crohn's Disease between 1986 and 2015: The Population-Based Songpa-Kangdong Inflammatory Bowel Disease Cohort Study
}

\author{
Byong Duk Ye', Sung Noh Hong ${ }^{2}$, Seung In Seo ${ }^{3}$, Ye-Jee Kim4, Jae Myung Cha ${ }^{5}$, Kyoung Hoon Rhee ${ }^{6}$, Hyuk \\ Yoon ${ }^{7}$, Young-Ho Kim ${ }^{2}$, Kyung Ho Kim ${ }^{3}$, Sun Yong Park ${ }^{8}$, Seung Kyu Jeong ${ }^{9}$, Ji Hyun Lee ${ }^{10}$, Hyunju Park ${ }^{11}$, Joo \\ Sung Kim ${ }^{12}$, Jong Pil Im², Sung Hoon Kim ${ }^{13}$, Jisun Jang ${ }^{13}$, Jeong Hwan Kim ${ }^{14}$, Seong O Suh ${ }^{15}$, Young Kyun Kim ${ }^{16}$, \\ Sang Hyoung Park', and Suk-Kyun Yang ${ }^{1}$, on behalf of the Songpa-Kangdong Inflammatory Bowel Disease (SK- \\ IBD) Study Group
}

${ }^{1}$ Department of Gastroenterology and Inflammatory Bowel Disease Center, Asan Medical Center, University of Ulsan College of Medicine, ${ }^{2}$ Department of Medicine, Samsung Medical Center, Sungkyunkwan University School of Medicine, ${ }^{3}$ Department of Internal Medicine, Kangdong Sacred Heart Hospital, Hallym University College of Medicine, ${ }^{4}$ Department of Clinical Epidemiology and Biostatistics, Asan Medical Center, University of Ulsan College of Medicine, ${ }^{5}$ Department of Internal Medicine, Kyung Hee University Hospital at Gangdong, Kyung Hee University College of Medicine, ${ }^{6}$ Department of Internal Medicine, Hansol Hospital, Seoul, ${ }^{7}$ Department of Internal Medicine, Seoul National University Bundang Hospital, Seongnam, ${ }^{8}$ Kangdong Seoul Colon and Rectal Surgery, ${ }^{9}$ Department of Surgery, Yang Hospital, ${ }^{10}$ Digestive Endoscopic Center, Seoul Song Do Colorectal Hospital, ${ }^{11}$ Department of Gastroenterology, Daehang Hospital, ${ }^{12}$ Department of Internal Medicine and Liver Research Institute, Seoul National University College of Medicine, ${ }^{13}$ Department of Internal Medicine, VHS Medical Center, ${ }^{14}$ Department of Internal Medicine, Konkuk University Medical Center, ${ }^{15}$ Department of Internal Medicine, National Police Hospital, and ${ }^{16}$ Jamsil Seoul Surgical Clinic, Seoul, Korea

Article Info

Received January 29, 2021

Revised March 23, 2021

Accepted April 12, 2021

Published online June 22, 2021

Corresponding Author

Suk-Kyun Yang

ORCID https://orcid.org/0000-0003-2772-2575

E-mail sky@amc.seoul.kr

Byong Duk Ye, Sung Noh Hong, and Seung In Seo contributed equally to this work as first authors.
Background/Aims: The long-term course of Crohn's disease (CD) has never been evaluated in non-Caucasian population-based cohorts. The aim of the present study was to evaluate the longterm prognosis of Korean CD patients in the well-defined population-based Songpa-Kangdong inflammatory bowel disease cohort.

Methods: Outcomes of disease and their predictors were evaluated for 418 patients diagnosed with CD between 1986 and 2015.

Results: During a median of 123 months, systemic corticosteroids, thiopurines, and anti-tumor necrosis factor (TNF) agents were administered to $58.6 \%, 81.3 \%$, and $37.1 \%$ of patients, respectively. Over time, the cumulative probability of starting corticosteroids significantly decreased $(p=0.001)$, whereas that of starting thiopurines and anti-TNFs significantly increased (both $p<0.001$ ). The cumulative probability of behavioral progression was $54.5 \%$ at 20 years, and it significantly decreased during the anti-TNF era. Intestinal resection was required for 113 patients (27.0\%). The cumulative probabilities of intestinal resection at $1,5,10,20$, and 25 years after CD diagnosis were $12.7 \%, 16.5 \%, 23.8 \%, 45.1 \%$, and $51.2 \%$, respectively. Multivariable Cox regression analysis identified stricturing behavior at diagnosis (adjusted hazard ratio [aHR], 2.70; 95\% confidence interval [Cl], 1.55 to 4.71$)$, penetrating behavior at diagnosis $(\mathrm{aHR}, 11.15 ; 95 \% \mathrm{Cl}$, 6.91 to 17.97 ), and diagnosis of CD during the anti-TNF era (aHR, $0.51 ; 95 \% \mathrm{Cl}, 0.35$ to 0.76 ) as independently associated with intestinal resection. The standardized mortality ratio among CD patients was $1.36(95 \% \mathrm{Cl}, 0.59$ to 2.68$)$.

Conclusions: The long-term prognosis of Korean patients with $C D$ is at least as good as that of Western CD patients, as indicated by the low intestinal resection rate. Moreover, behavioral progression and intestinal resection rates have decreased over the past 3 decades. (Gut Liver 2022;16:216-227)

Key Words: SK-IBD; Crohn disease; Prognosis; Korea 


\section{INTRODUCTION}

Crohn's disease (CD) was previously known as a disease that primarily affects people from the Western hemisphere, but its incidence is rapidly increasing in Asia alongside the ever-increasing adoption of Western lifestyle and cultural influences on the continent. ${ }^{1-3}$ According to the Songpa-Kangdong inflammatory bowel disease (SKIBD) study, which investigated a well-defined populationbased IBD patient cohort from the Songpa-Kangdong district of Seoul, Korea, the mean annual incidence of CD has increased from 0.06/100,000 during 1986 and 1990 to $2.44 / 100,000$ during 2011 and $2015 .{ }^{4}$ However, both the genotypic and phenotypic characteristics of $\mathrm{CD}$ in Asians are known to be different from those in Westerners in many aspects. For example, NOD2 is associated with $\mathrm{CD}$ susceptibility and prognosis in Caucasians but not in Asians, whereas TNFSF15 is more strongly associated with $\mathrm{CD}$ in Asians than in Caucasians. ${ }^{5,6}$ Additionally, previous Asian studies have demonstrated that, in contrast with Western patients, CD has a male preponderance among Asians, along with a high frequency of perianal fistula and a low proportion of isolated colonic disease. ${ }^{4,7-12}$ These differences raise the possibility that the natural history of $\mathrm{CD}$ among Asians may also differ from that among Westerners. Understanding the long-term prognosis of CD among Asian population is crucial for the proper management of individual patients as well as for developing optimal health care strategies. However, there has been a lack of population-based studies on the long-term outcomes of CD in non-Caucasian populations. Previous investigations on the long-term clinical courses and outcomes of Asian patients with $\mathrm{CD}$ should be interpreted with caution because they were hospital-based studies, ${ }^{8,10,13-16}$ and recent populationbased studies from Asia were limited by their short followup periods. ${ }^{17-19}$

Therefore, the aim of the present study was to investigate the long-term course of Korean patients diagnosed with CD between 1986 and 2015 using the SK-IBD cohort. We particularly aimed to evaluate the changes in the prognosis of $\mathrm{CD}$ after the introduction of anti-tumor necrosis factor (TNF) agents in clinical practice.

\section{MATERIALS AND METHODS}

\section{Study area and population}

The SK-IBD study was conducted in the Songpa-Kangdong district, which is a well-defined administrative division in Seoul, Korea, from 1986 (year of diagnosis of the first IBD case) through 2015. ${ }^{4}$ During the patient enroll- ment period for 30 years, the Songpa-Kangdong district had ethnically homogeneous population (predominantly Koreans), which has gradually increased in its number, from 936,097 in 1986 to $1,118,960$ inhabitants in $2015 .{ }^{4}$ All inhabitants in the region were covered by a unified public health insurance system with an easy accessibility to medical care at any time. The protocol of the present study was approved by the institutional review boards of all participating institutions, including Asan Medical Center (IRB number: 2012-0634), and the SK-IBD cohort is registered at ClinicalTrials.gov (NCT01731665). The informed consent requirements were waived by the institutional review boards.

\section{Case identification and ascertainment}

A prospective IBD registry was established on January 1, 1997, in the Songpa-Kangdong district. Patients diagnosed before 1997 were retrospectively added to the registry, and those diagnosed since 1997 were prospectively enrolled. The quality of data was verified and maintained through careful review of data by two of the authors (S.K.Y. and B.D.Y.), regular meetings of investigators, and study site visits by a central research coordinator. The data used in the present study were collected through March 2020.

\section{Study design}

Using unified case report forms, baseline demographic and clinical characteristics, including sex, age at diagnosis of $\mathrm{CD}$, date of $\mathrm{CD}$ diagnosis, interval from onset of symptoms to CD diagnosis, family history of IBD, smoking status at diagnosis, disease location at diagnosis, and disease behavior at diagnosis were collected. Additionally, for investigating the subsequent progression of disease, medication use, behavioral progression, intestinal resection, hospitalization, and survival were evaluated throughout the follow-up period. To evaluate the temporal trends in the prognosis of $\mathrm{CD}$ according to a change in treatment paradigm, patients were divided into two temporal cohorts according to the year of CD diagnosis: Cohort 1 (19862003) and Cohort 2 (2004-2015). This division was chosen in consideration of the commencement of reimbursement for anti-TNF agents in September 2003.

\section{Definitions}

Diagnosis of $\mathrm{CD}$ was made by combining conventional clinical, endoscopic, radiologic, and histopathologic criteria. $^{7,20,21}$ The date of $\mathrm{CD}$ diagnosis was defined as the date of the first endoscopic or radiologic evaluation showing findings consistent with $\mathrm{CD}$. If the diagnosis changed from ulcerative colitis or IBD unclassified to CD during observation, the date of the initial IBD diagnosis was defined 
as the date of diagnosis of $\mathrm{CD}$. The Montreal classification was used for defining CD phenotypes. ${ }^{22}$ Behavioral progression was defined as the development of $\mathrm{B} 2$ or $\mathrm{B} 3$ among patients with $\mathrm{B} 1$ at the time of $\mathrm{CD}$ diagnosis. ${ }^{23}$ The date of behavioral progression was defined as the date of diagnosing B2 or B3, whichever came first. Regarding medical therapy, early use of corticosteroids was defined as treatment started within 3 months of $\mathrm{CD}$ diagnosis. ${ }^{10,24}$ Early use of thiopurines or anti-TNF agents was defined as the commencement of therapy within 6 months of diagno$\operatorname{sis}^{23}$ and at least 6 months before behavioral progression, the first intestinal resection, or the first hospitalization. ${ }^{10,25}$ Hospitalization was defined as admission for managing disease flare-ups, either medically or surgically. We excluded admissions that were only for disease evaluation or drug administration, as well as those that were shorter than 3 days or unrelated to $\mathrm{CD}^{23,26}$

\section{Treatment policy}

The therapeutic strategies for CD in Korea have been previously described in detail ${ }^{8,10,27}$ and are not different from those in Western countries, excluding therapeutic sequences involving biologic agents. We treat patients with CD based on a "step-up approach." ${ }^{28}$ Systemic corticosteroids are used for short-term treatment of flare-ups, and immunomodulators are used as maintenance therapy. Anti-TNF agents have been reimbursed for treating $\mathrm{CD}$ since September 2003. However, owing to the strict criteria for reimbursement by Korean government, biologics can only be reimbursed for moderate to severe $\mathrm{CD}$ patients who are not responding to both corticosteroids and immunomodulators. Therefore, the "top-down approach" with upfront biologic agents is not reimbursable and is rarely used. Vedolizumab and ustekinumab have been reimbursable since August 2017 and December 2018, respectively, and are occasionally prescribed for patients who have previously failed anti-TNF therapy.

\section{Statistical analysis}

Continuous variables are expressed as medians with interquartile ranges (IQRs) or ranges and categorical variables are expressed as numbers with percentages. For

Table 1. Demographic and Clinical Characteristics of 418 Patients with Crohn's Disease in the Songpa-Kangdong District of Seoul, Korea, in $1986-2015$

\begin{tabular}{|c|c|c|c|c|}
\hline \multirow{2}{*}{ Clinical characteristics } & \multicolumn{4}{|c|}{ Year of diagnosis } \\
\hline & Total & Cohort 1 (1986-2003) & Cohort 2 (2004-2015) & $\mathrm{p}$-value \\
\hline No. of patients & $418(100)$ & $110(26.3)$ & 308 (73.7) & \\
\hline Male sex & $318(76.1)$ & 83 (75.5) & 235 (76.3) & 0.897 \\
\hline Age at diagnosis, median (IQR), yr & $22(18-29)$ & $21(17-27)$ & $23(18-31)$ & 0.089 \\
\hline Age at diagnosis, yr & & & & 0.072 \\
\hline$\leq 16$ (A1) & $56(13.4)$ & $16(14.6)$ & 40 (13.0) & \\
\hline $17-40(\mathrm{~A} 2)$ & 324 (77.5) & 90 (81.8) & 234 (76.0) & \\
\hline$>40$ (A3) & $38(9.1)$ & $4(3.6)$ & $34(11.0)$ & \\
\hline Interval from symptom onset to diagnosis, median (IQR), mo & $10.0(3.2-35.0)$ & $14.8(5.5-37.7)$ & $8.9(2.6-29.8)$ & 0.005 \\
\hline Current smoking at diagnosis & $118(28.2)$ & 34 (30.9) & $84(27.3)$ & 0.537 \\
\hline Family history of IBD & $32(7.7)$ & 9 (8.2) & $23(7.5)$ & 0.835 \\
\hline Disease location at diagnosis & & & & 0.525 \\
\hline Ileum (L1) & 104 (24.9) & $23(20.9)$ & $81(26.3)$ & \\
\hline Colon (L2) & $39(9.3)$ & $10(9.1)$ & $29(9.4)$ & \\
\hline Ileocolon (L3) & 275 (65.8) & $77(70.0)$ & 198 (64.3) & \\
\hline Upper GI involvement (L4) & 94 (22.5) & 19 (17.3) & 75 (24.4) & 0.144 \\
\hline Disease behavior at diagnosis & & & & 0.814 \\
\hline Nonstricturing, nonpenetrating (B1) & $339(81.1)$ & $91(82.7)$ & $248(80.5)$ & \\
\hline Stricturing (B2) & $34(8.1)$ & 9 (8.2) & $25(8.1)$ & \\
\hline Penetrating (B3) & 45 (10.8) & $10(9.1)$ & $35(11.4)$ & \\
\hline Perianal fistula before or at diagnosis & $181(43.3)$ & $49(44.5)$ & $132(42.9)$ & 0.823 \\
\hline Duration of follow-up, median (IQR), mo & $123.7(78.9-181.1)$ & $223.4(200.1-256.3)$ & $100.8(70.2-135.6)$ & $<0.001$ \\
\hline \multicolumn{5}{|l|}{ Ever use of medications } \\
\hline Systemic corticosteroids & $245(58.6)$ & 83 (75.5) & $162(52.6)$ & $<0.001$ \\
\hline Thiopurines & 340 (81.3) & $88(80.0)$ & 252 (81.8) & 0.776 \\
\hline Methotrexate & $11(2.6)$ & $3(2.7)$ & $8(2.6)$ & 0.645 \\
\hline Anti-TNF agents & $155(37.1)$ & $46(41.8)$ & $109(35.4)$ & 0.251 \\
\hline Vedolizumab & $4(1.0)$ & $3(2.7)$ & $1(0.3)$ & 0.058 \\
\hline Ustekinumab & $6(1.4)$ & 2 (1.8) & $4(1.3)$ & $>0.999$ \\
\hline
\end{tabular}

Data are presented as number (\%) unless otherwise indicated.

$I Q R$, interquartile range; IBD, inflammatory bowel disease; GI, gastrointestinal; TNF, tumor necrosis factor. 
comparing continuous variables, the Mann-Whitney U test was used. The chi-square test or the Fisher exact test was used to compare categorical variables, as appropriate. Cumulative probabilities of drug use, behavioral progression, intestinal resection, hospitalization, and survival were analyzed using the Kaplan-Meier method, and group values were compared using the log-rank test. Multivariable Cox regression analysis with the stepwise selection method using variables with p-values less than 0.1 in the univariate Cox regression analysis was conducted to identify significant predictors of the cumulative probabilities of behavioral progression, intestinal resection, hospitalization, and to calculate their hazard ratios (HRs) and 95\% confidence intervals (CIs). To evaluate the effect of early use of corticosteroids, thiopurines, and anti-TNF agents on behavioral progression, intestinal resection, and hospitalization, an additional multivariable Cox regression analysis was performed after excluding patients who experienced behavioral progression, intestinal resection, and hospitalization, respectively, within 6 months of diagnosis.

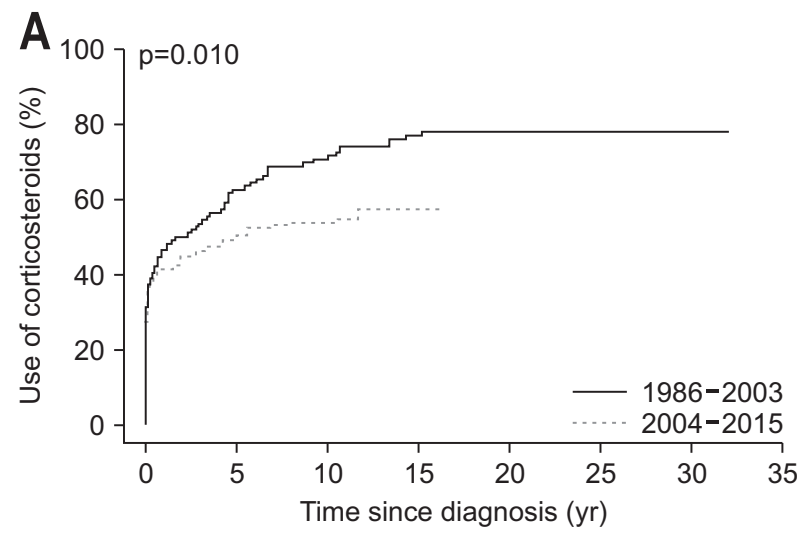

\begin{tabular}{cccccc}
\hline Cumulative risk & $1 \mathrm{yr}$ & $5 \mathrm{yr}$ & $10 \mathrm{yr}$ & $20 \mathrm{yr}$ & $30 \mathrm{yr}$ \\
\hline $1986-2003$ & $45.5 \%$ & $62.6 \%$ & $70.7 \%$ & $78.2 \%$ & $78.2 \%$ \\
$2004-2015$ & $41.3 \%$ & $49.2 \%$ & $53.9 \%$ & - & - \\
\hline
\end{tabular}

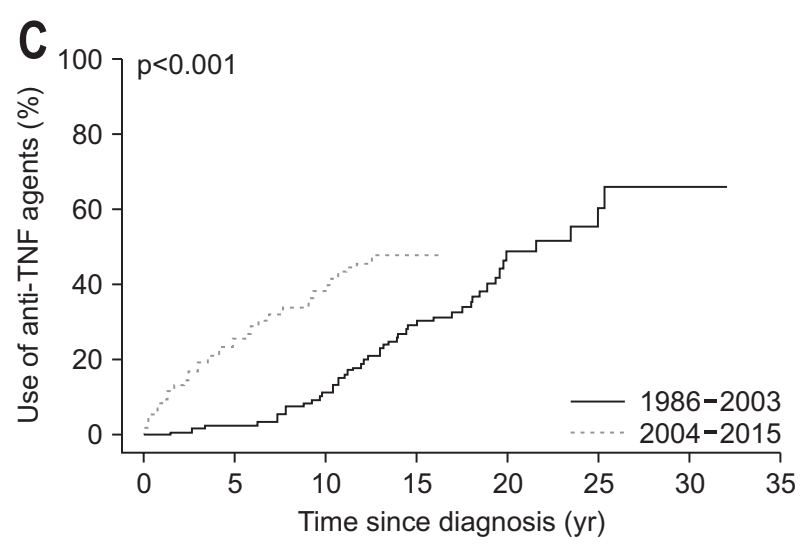

\begin{tabular}{ccrrrc}
\hline Cumulative risk & $1 \mathrm{yr}$ & \multicolumn{1}{c}{$5 \mathrm{yr}$} & $10 \mathrm{yr}$ & $20 \mathrm{yr}$ & $30 \mathrm{yr}$ \\
\hline $1986-2003$ & $0.0 \%$ & $2.8 \%$ & $11.4 \%$ & $49.1 \%$ & $66.3 \%$ \\
$2004-2015$ & $8.8 \%$ & $24.5 \%$ & $38.6 \%$ & - & - \\
\hline
\end{tabular}

Standardized mortality ratios (i.e., the ratio of the observed to the expected number of deaths) were calculated to compare the mortality of $\mathrm{CD}$ patients with that of the general population. The Poisson distribution was applied for calculating the $95 \%$ CIs of the standardized mortality ratios. The mortality data of the total Korean population was obtained from the Korean Statistical Information Service. ${ }^{30}$ Two-sided p-values less than 0.05 were considered to be statistically significant. Statistical analyses were performed using IBM SPSS Statistics for Windows, version 23.0 (IBM Corp., Armonk, NY, USA) or SAS, version 9.4 (SAS Institute, Cary, NC, USA).

\section{RESULTS}

\section{Characteristics of patients}

A total of 418 patients were diagnosed with $\mathrm{CD}$ from January 1986 through December 2015: 110 in 1986-2003 (Cohort 1) and 308 in 2004-2015 (Cohort 2). Character-

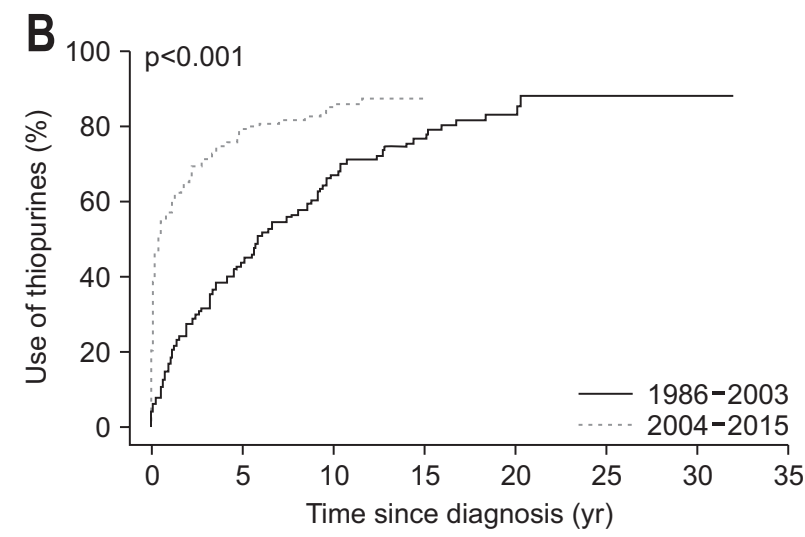

\begin{tabular}{cccccc}
\hline Cumulative risk & $1 \mathrm{yr}$ & $5 \mathrm{yr}$ & $10 \mathrm{yr}$ & $20 \mathrm{yr}$ & $30 \mathrm{yr}$ \\
\hline $1986-2003$ & $16.4 \%$ & $43.3 \%$ & $67.3 \%$ & $83.1 \%$ & $87.9 \%$ \\
$2004-2015$ & $57.4 \%$ & $78.3 \%$ & $84.6 \%$ & - & - \\
\hline
\end{tabular}

Fig. 1. Temporal trends in the cumulative probability of medication use among patients with Crohn's disease: (A) corticosteroids, (B) thiopurines, and (C) anti-tumor necrosis factor (anti-TNF) agents. 
istics of patients at diagnosis are presented in Table 1. The proportion of males, age at diagnosis, current smokers at diagnosis, disease location and behavior at diagnosis, and perianal fistulas before or at diagnosis were not different between the two cohorts. However, the interval from symptom onset to diagnosis was significantly shorter in Cohort 2 than Cohort $1(\mathrm{p}=0.005)$. The median duration of follow-up was 123.7 months (IQR, 78.9 to 181.1 months).

\section{Medical treatment}

Systemic corticosteroids, thiopurines, anti-TNF agents, vedolizumab, and ustekinumab were given to $58.6 \%$, $81.3 \%, 37.1 \%, 1.0 \%$, and $1.4 \%$ of patients, respectively,

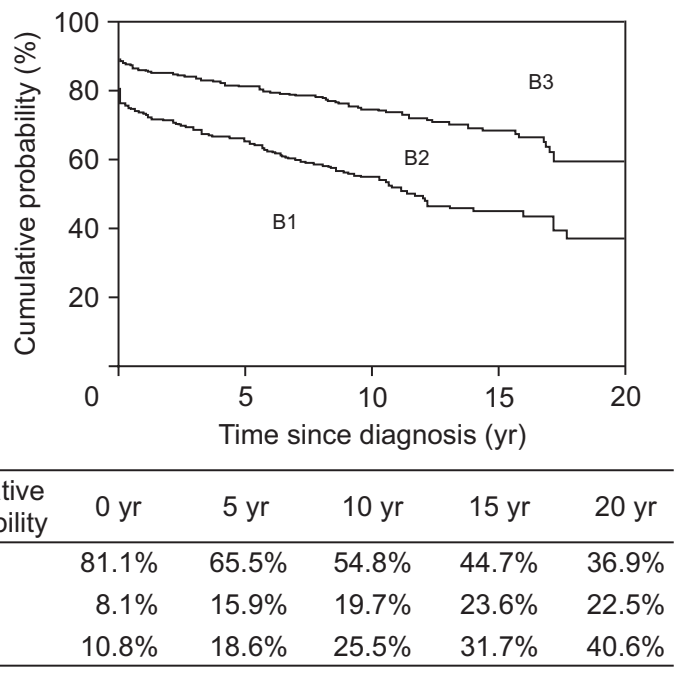

Fig. 2. Kaplan-Meier curves depicting the probabilities of remaining free of penetrating complications (upper curve) and free of stricturing or penetrating complications (lower curve) among patients with Crohn's disease. B1, nonstricturing, nonpenetrating; B2, stricturing; $\mathrm{B} 3$, penetrating.

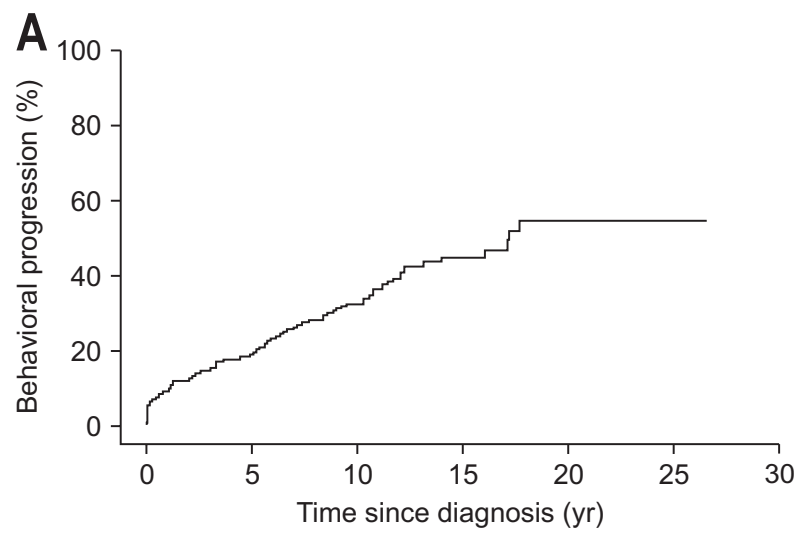

\begin{tabular}{cccccc}
\hline Cumulative risk & $1 \mathrm{yr}$ & $5 \mathrm{yr}$ & $10 \mathrm{yr}$ & $20 \mathrm{yr}$ & $25 \mathrm{yr}$ \\
\hline $1986-2015$ & $9.2 \%$ & $19.3 \%$ & $32.5 \%$ & $54.5 \%$ & $54.5 \%$ \\
\hline
\end{tabular}

from diagnosis or during follow-up (Table 1). Median intervals from diagnosis of $\mathrm{CD}$ to medication commencement were 0.9 months (IQR, 0 to 18.6 months) for corticosteroids, 7.0 months (IQR, 1.1 to 40.5 months) for thiopurines, and 61.4 months (IQR, 21.1 to 124.3 months) for anti-TNF agents. The cumulative probabilities of initiating each medication at $1,5,10,20$, and 30 years after diagnosis of $\mathrm{CD}$ were $42.4 \%, 52.8 \%, 58.9 \%, 67.4 \%$, and $67.4 \%$, respectively, for corticosteroids; $46.6 \%, 68.9 \%, 80.3 \%, 89.6 \%$, and $92.6 \%$, respectively, for thiopurines; and $6.5 \%, 18.7 \%$, $30.7 \%, 60.0 \%$, and $73.5 \%$, respectively, for anti-TNF agents. Temporal changes in the cumulative probabilities of commencing medications between Cohort 1 and Cohort 2 are presented in Fig. 1. The cumulative probability of commencing medications significantly decreased for corticosteroids $(\mathrm{p}=0.010)$ but significantly increased for thiopurines and anti-TNF agents (both $\mathrm{p}<0.001$ ). Additionally, the median interval from diagnosis of $\mathrm{CD}$ to medication commencement was significantly shorter in Cohort 2 than Cohort 1: 2.7 months versus 0.5 months for corticosteroids $(\mathrm{p}=0.006), 53.0$ months versus 3.0 months for thiopurines $(\mathrm{p}<0.001)$, and 155.6 months versus 36.9 months for antiTNF agents $(\mathrm{p}<0.001)$.

\section{Changes in disease behavior}

Among the 339 patients with initial B1, 116 patients (34.2\%) progressed to either B2 or B3. The Kaplan-Meier curves presented in Fig. 2 were generated using the data of all 418 patients and depict the probability of remaining free of B2 or B3 complications. Among the 339 patients with initial B1, the cumulative probabilities of behavioral progression at $1,5,10$, and 20 years after diagnosis were $9.2 \%$, $19.3 \%, 32.5 \%$, and $54.5 \%$, respectively (Fig. $3 \mathrm{~A}$ ), and were significantly lower in Cohort 2 than in Cohort $1(\mathrm{p}<0.001)$

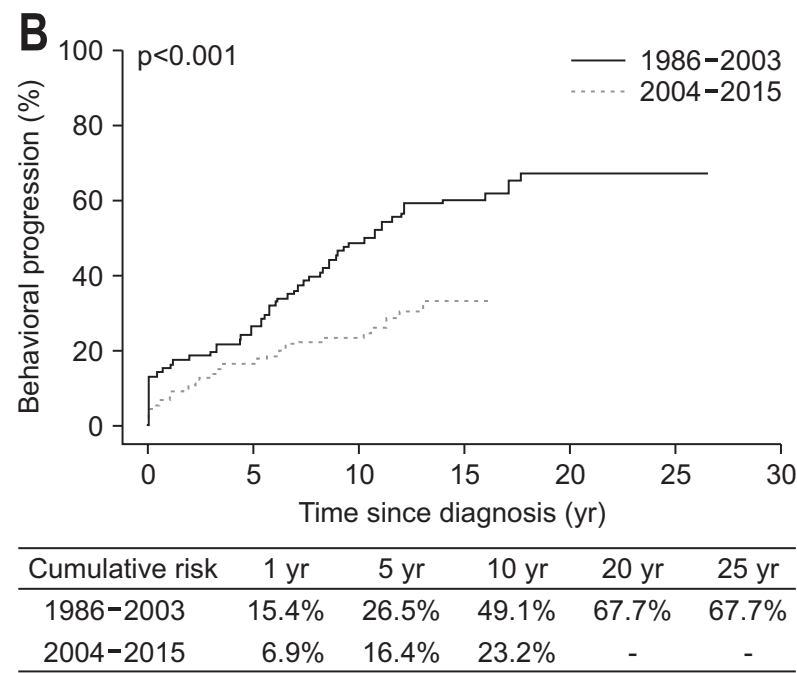

Fig. 3. Cumulative risk of behavioral progression among patients with Crohn's disease: $(A)$ in the entire cohort and (B) in the two temporal cohorts. 
(Fig. 3B). Multivariable Cox regression analysis revealed year of diagnosis (adjusted HR $[\mathrm{aHR}]_{2004-2015}, 0.54$; 95\% CI, 0.37 to 0.81 ) as a predictor of behavioral progression (Table 2 ). When analyzed after excluding 23 patients who showed behavioral progression within 6 months of diagnosis, in addition to year of diagnosis, family history of IBD was an independent predictor of behavioral progression (aHR, 2.01; 95\% CI, 1.10 to 3.70) (Table 3).

\section{Intestinal resection}

A total of 113 patients (27.0\%) underwent intestinal resection, with a median time to intestinal resection of 26.5 months (IQR, 0 to 111.7 months). The cumulative probabilities of intestinal resection at $1,5,10,20$, and 25 years after diagnosis were $12.7 \%, 16.5 \%, 23.8 \%, 45.1 \%$, and $51.2 \%$, respectively (Fig. 4A). The cumulative probability of intestinal resection was significantly lower in Cohort 2 than Cohort 1 ( $\mathrm{p}=0.002$ ) (Fig. 4B). When analyzed in patient subgroups according to disease location and behavior at diagnosis, this difference in the cumulative probability of intestinal resection between the two cohorts was observed in subgroups of patients with L1 and L3 (L1, p=0.031; L2, $\mathrm{p}=0.754 ; \mathrm{L} 3, \mathrm{p}=0.004$ ) (Supplementary Fig. 1) and in those with B1 (B1, p<0.001; B2, p=0.111; B3, p=0.849) (Supplementary Fig. 2).

Multivariable Cox regression analysis identified that

Table 2. Factors Associated with Behavioral Progression, Intestinal Resection, and Hospitalization

\begin{tabular}{|c|c|c|c|c|c|c|}
\hline \multirow{2}{*}{ Factor } & \multicolumn{2}{|c|}{$\begin{array}{l}\text { Risk of behavioral progression } \\
\qquad(\mathrm{n}=339]\end{array}$} & \multicolumn{2}{|c|}{$\begin{array}{l}\text { Risk of intestinal resection } \\
\qquad(\mathrm{n}=418)\end{array}$} & \multicolumn{2}{|c|}{$\begin{array}{l}\text { Risk of hospitalization } \\
\qquad(n=418)\end{array}$} \\
\hline & $\begin{array}{l}\text { Unadjusted HR } \\
\qquad(95 \% \mathrm{Cl})\end{array}$ & $\begin{array}{l}\text { Adjusted HR } \\
\left(95 \% \mathrm{CI}^{+}\right.\end{array}$ & $\begin{array}{l}\text { Unadjusted HR } \\
\qquad(95 \% \mathrm{CI})\end{array}$ & $\begin{array}{l}\text { Adjusted HR } \\
\qquad\left(95 \% \mathrm{Cl}^{\ddagger}\right.\end{array}$ & $\begin{array}{l}\text { Unadjusted HR } \\
\qquad(95 \% \mathrm{CI})\end{array}$ & $\begin{array}{l}\text { Adjusted HR } \\
(95 \% \mathrm{Cl})^{\S}\end{array}$ \\
\hline \multicolumn{7}{|l|}{ Sex } \\
\hline Male & Reference & Not included & Reference & Not included & Reference & Not included \\
\hline Female & $0.81(0.51-1.29)$ & & $0.92(0.59-1.43)$ & & $1.01(0.74-1.38)$ & \\
\hline \multicolumn{7}{|l|}{ Age at diagnosis, yr } \\
\hline$\leq 16$ (A1) & Reference & Not included & Reference & Not included & Reference & Not included \\
\hline $17-40$ (A2) & $1.29(0.76-2.21)$ & & $1.29(0.72-2.31)$ & & $0.76(0.53-1.09)$ & \\
\hline$>40$ (A3) & $0.64(0.24-1.75)$ & & $1.39(0.61-3.18)$ & & $0.67(0.37-1.19)$ & \\
\hline $\begin{array}{l}\text { Symptom onset to diagnosis, } \\
\text { (per mo) }\end{array}$ & $1.00(1.00-1.01)$ & Not included & $1.00(1.00-1.01)$ & Not included & $1.00(1.00-1.01)$ & $1.00(1.00-1.00)$ \\
\hline \multicolumn{7}{|l|}{ Cohort } \\
\hline 1986-2003 & Reference & Reference & Reference & Reference & Reference & Reference \\
\hline $2004-2015$ & $0.53(0.36-0.79)$ & $0.54(0.37-0.81)^{*}$ & $0.55(0.37-0.81)$ & $0.51(0.35-0.76)^{*}$ & $0.55(0.42-0.73)$ & $0.57(0.43-0.75)^{*}$ \\
\hline \multicolumn{7}{|l|}{ Current smoking at diagnosis } \\
\hline No & Reference & Not included & Reference & Reference & Reference & Reference \\
\hline Yes & $1.34(0.89-2.03)$ & & $1.56(1.07-2.28)$ & $1.31(0.89-1.94)$ & $1.41(1.07-1.87)$ & $1.08(0.81-1.44)$ \\
\hline \multicolumn{7}{|l|}{ Family history of IBD } \\
\hline No & Reference & Reference & Reference & Not included & Reference & Not included \\
\hline Yes & $1.71(0.94-3.12)$ & $1.68(0.92-3.06)$ & $1.28(0.68-2.38)$ & & $1.00(0.61-1.63)$ & \\
\hline \multicolumn{7}{|l|}{ Disease location at diagnosis } \\
\hline Colon (L2) & Reference & Not included & Reference & Reference & Reference & Not included \\
\hline Ileum (L1) & $2.04(0.85-4.90)$ & & $6.08(2.16-17.14)$ & $4.17(1.43-12.20)^{*}$ & $1.36(0.80-2.31)$ & \\
\hline Ileocolon (L3) & $2.08(0.96-4.51)$ & & $2.94(1.07-8.08)$ & $4.04(1.44-11.34)^{*}$ & $1.04(0.63-1.69)$ & \\
\hline \multicolumn{7}{|l|}{ Upper GI involvement (L4) } \\
\hline No & Reference & Reference & Reference & Reference & Reference & Not included \\
\hline Yes & $0.58(0.34-1.01)$ & $0.59(0.34-1.02)$ & $0.53(0.30-0.93)$ & $0.61(0.35-1.08)$ & $0.82(0.58-1.15)$ & \\
\hline \multicolumn{7}{|l|}{ Disease behavior at diagnosis } \\
\hline Nonstricturing, nonpenetrating (B1) & - & - & Reference & Reference & Reference & Reference \\
\hline Stricturing (B2) & - & - & $3.05(1.78-5.26)$ & $2.70(1.55-4.71) *$ & $2.28(1.53-3.39)$ & $2.18(1.46-3.27) *$ \\
\hline Penetrating (B3) & - & - & 11.87 (7.76-18.18) & $11.15(6.91-17.97)^{*}$ & $6.48(4.48-9.37)$ & $6.00(4.07-8.82)^{*}$ \\
\hline \multicolumn{7}{|l|}{ Perianal fistula before or at diagnosis } \\
\hline No & Reference & Not included & Reference & Reference & Reference & Reference \\
\hline Yes & $1.13(0.77-1.65)$ & & $0.63(0.43-0.93)$ & $0.82(0.55-1.23)$ & $0.73(0.55-0.96)$ & $0.80(0.60-1.06)$ \\
\hline
\end{tabular}

$\mathrm{HR}$, hazard ratio; $\mathrm{Cl}$, confidence interval; IBD, inflammatory bowel disease; $\mathrm{Gl}$, gastrointestinal.

${ }^{*} p<0.05 ;{ }^{\dagger}$ Model included the following covariates: cohort (1986-2003 or 2004-2015), family history of IBD, and upper GI involvement; ${ }^{\ddagger}$ Model included the following covariates: cohort (1986-2003 or 2004-2015), current smoking at diagnosis, disease location at diagnosis, upper GI involvement, disease behavior at diagnosis, and perianal fistula at or before diagnosis; ${ }^{\S}$ Model included the following covariates: symptom onset to diagnosis, cohort (1986-2003 or 2004-2015), current smoking at diagnosis, disease behavior at diagnosis, and perianal fistula at or before diagnosis. 
Table 3. Factors Associated with Behavioral Progression, Intestinal Resection, and Hospitalization, Excluding Events That Occurred within 6 Months of Diagnosis

\begin{tabular}{|c|c|c|c|c|c|c|}
\hline \multirow{2}{*}{ Factor } & \multicolumn{2}{|c|}{$\begin{array}{l}\text { Risk of behavioral progression } \\
\qquad(\mathrm{n}=316)\end{array}$} & \multicolumn{2}{|c|}{$\begin{array}{l}\text { Risk of intestinal resection } \\
\qquad(n=370)\end{array}$} & \multicolumn{2}{|c|}{$\begin{array}{l}\text { Risk of hospitalization } \\
\qquad(\mathrm{n}=299)\end{array}$} \\
\hline & $\begin{array}{l}\text { Unadjusted HR } \\
\qquad(95 \% \mathrm{CI})\end{array}$ & $\begin{array}{l}\text { Adjusted HR } \\
\left(95 \% \mathrm{Cl}^{+}\right.\end{array}$ & $\begin{array}{l}\text { Unadjusted HR } \\
\qquad(95 \% \mathrm{CI})\end{array}$ & $\begin{array}{l}\text { Adjusted HR } \\
(95 \% \mathrm{Cl})^{\ddagger}\end{array}$ & $\begin{array}{l}\text { Unadjusted HR } \\
\qquad(95 \% \mathrm{CI})\end{array}$ & $\begin{array}{l}\text { Adjusted HR } \\
(95 \% \mathrm{Cl})^{\S}\end{array}$ \\
\hline \multicolumn{7}{|l|}{ Sex } \\
\hline Male & Reference & Not included & Reference & Not included & Reference & Not included \\
\hline Female & $0.81(0.49-1.33)$ & & $0.67(0.36-1.25)$ & & $0.98(0.61-1.57)$ & \\
\hline \multicolumn{7}{|l|}{ Age at diagnosis, yr } \\
\hline$\leq 16(\mathrm{~A} 1)$ & Reference & Not included & Reference & Not included & Reference & Not included \\
\hline $17-40$ (A2) & $1.21(0.69-2.11)$ & & $1.15(0.57-2.33)$ & & $0.61(0.36-1.02)$ & \\
\hline$>40(\mathrm{~A} 3)$ & $0.56(0.19-1.68)$ & & $0.68(0.18-2.51)$ & & $0.49(0.21-1.18)$ & \\
\hline $\begin{array}{l}\text { Symptom onset to diagnosis } \\
\text { (per mo) }\end{array}$ & $1.00(1.00-1.01)$ & Not included & $1.00(1.00-1.01)$ & Not included & $1.00(1.00-1.01)$ & Not included \\
\hline \multicolumn{7}{|l|}{ Cohort } \\
\hline 1986-2003 & Reference & Reference & Reference & Reference & Reference & Reference \\
\hline $2004-2015$ & $0.50(0.33-0.76)$ & $0.50(0.33-0.77)^{*}$ & $0.41(0.240-0.70)$ & $0.49(0.28-0.85)^{*}$ & $0.45(0.30-0.68)$ & $0.51(0.33-0.79) *$ \\
\hline \multicolumn{7}{|l|}{ Current smoking at diagnosis } \\
\hline No & Reference & Not included & Reference & Reference & Reference & Reference \\
\hline Yes & $1.30(0.83-2.02)$ & & $1.56(0.94-2.57)$ & $1.36(0.82-2.28)$ & $1.51(0.99-2.29)$ & $1.27(0.82-1.95)$ \\
\hline \multicolumn{7}{|l|}{ Family history of IBD } \\
\hline No & Reference & Reference & Reference & Reference & Reference & Not included \\
\hline Yes & $2.07(1.13-3.79)$ & $2.01(1.10-3.70)^{*}$ & $1.91(0.94-3.87)$ & $1.96(0.95-4.03)$ & $1.00(0.49-2.08)$ & \\
\hline \multicolumn{7}{|l|}{ Disease location at diagnosis } \\
\hline Colon (L2) & Reference & Not included & Reference & Not included & Reference & Not included \\
\hline Ileum (L1) & $1.91(0.73-5.00)$ & & $3.49(0.99-12.30)$ & & $1.10(0.48-2.49)$ & \\
\hline Ileocolon (L3) & $2.22(0.97-5.12)$ & & $3.08(0.96-9.95)$ & & $1.12(0.54-2.32)$ & \\
\hline \multicolumn{7}{|l|}{ Upper Gl involvement (L4) } \\
\hline No & Reference & Not included & Reference & Not included & Reference & Not included \\
\hline Yes & $0.64(0.36-1.13)$ & & $0.66(0.33-1.33)$ & & $0.84(0.51-1.41)$ & \\
\hline \multicolumn{7}{|l|}{ Disease behavior at diagnosis } \\
\hline Nonstricturing, nonpenetrating (B1) & - & - & Reference & Reference & Reference & Reference \\
\hline Stricturing (B2) & - & - & $2.44(1.23-4.82)$ & $2.18(1.09-4.35)^{*}$ & $2.37(1.34-4.21)$ & $2.24(1.25-3.99) *$ \\
\hline Penetrating (B3) & - & - & $3.42(1.46-8.03)$ & $4.93(2.02-12.08)^{*}$ & $3.62(1.31-10.00)$ & $2.88(1.02-8.18)^{*}$ \\
\hline \multicolumn{7}{|l|}{ Perianal fistula before or at diagnosis } \\
\hline No & Reference & Not included & Reference & Not included & Reference & Not included \\
\hline Yes & $1.03(0.68-1.55)$ & & $0.88(0.54-1.44)$ & & $0.87(0.58-1.30)$ & \\
\hline Early use of corticosteroids & $0.90(0.59-1.37)$ & Not included & $1.06(0.65-1.73)$ & Not included & $0.81(0.53-1.26)$ & Not included \\
\hline Early use of thiopurines & $0.77(0.47-1.25)$ & Not included & $0.46(0.23-0.94)$ & $0.47(0.22-1.01)$ & $0.53(0.32-0.89)$ & $0.67(0.39-1.16)$ \\
\hline Early use of anti-TNF agents & $0.53(0.13-2.16)$ & Not included & $0.55(0.08-3.97)$ & Not included & $0.05(0.00-10.13)$ & Not included \\
\hline
\end{tabular}

$\mathrm{HR}$, hazard ratio; $\mathrm{Cl}$, confidence interval; IBD, inflammatory bowel disease; GI, gastrointestinal; TNF, tumor necrosis factor.

${ }^{*} p<0.05 ;{ }^{\dagger}$ Model included the following covariates: cohort (1986-2003 or 2004-2015), and family history of IBD; ${ }^{\ddagger}$ Model included the following covariates: cohort (1986-2003 or 2004-2015), current smoking at diagnosis, family history of IBD, disease behavior at diagnosis, and early use of thiopurines; ${ }^{\S}$ Model included the following covariates: cohort (1986-2003 or 2004-2015), current smoking at diagnosis, disease behavior at diagnosis, and early use of thiopurines.

disease location at diagnosis $\left(\mathrm{aHR}_{\mathrm{L} 1}, 4.17 ; 95 \% \mathrm{CI}, 1.43\right.$ to 12.20 and $\mathrm{aHR}_{\mathrm{L} 3}, 4.04$; 95\% CI, 1.44 to 11.34$)$, disease behavior at diagnosis $\left(\mathrm{aHR}_{\mathrm{B} 2}, 2.70\right.$; $95 \% \mathrm{CI}, 1.55$ to 4.71 and $\mathrm{aHR}_{\mathrm{B} 3}, 11.15 ; 95 \% \mathrm{CI}, 6.91$ to 17.97$)$, and year of diagnosis $\left(\mathrm{aHR}_{2004-2015}, 0.51 ; 95 \% \mathrm{CI}, 0.35\right.$ to 0.76$)$ were independent predictors of intestinal resection (Table 2). When analyzed after excluding 48 patients who underwent intestinal resection within 6 months of diagnosis, disease behavior at diagnosis and year of diagnosis remained independent predictors of intestinal resection, and early use of thiopurines was marginally associated with intestinal resection (aHR, $0.47 ; 95 \%$ CI, 0.22 to 1.01 ) (Table 3 ).

\section{Hospitalization}

At CD diagnosis or during follow-up, a total of 216 patients (51.7\%) were hospitalized and the median time to the first hospitalization was 2.6 months (IQR, 0 to 47.2 months). The indications for the first hospitalizations were $\mathrm{CD}$ aggravations managed by medical therapy in $146 \mathrm{pa}-$ tients (67.6\%) and $\mathrm{CD}$ complications leading to intestinal 

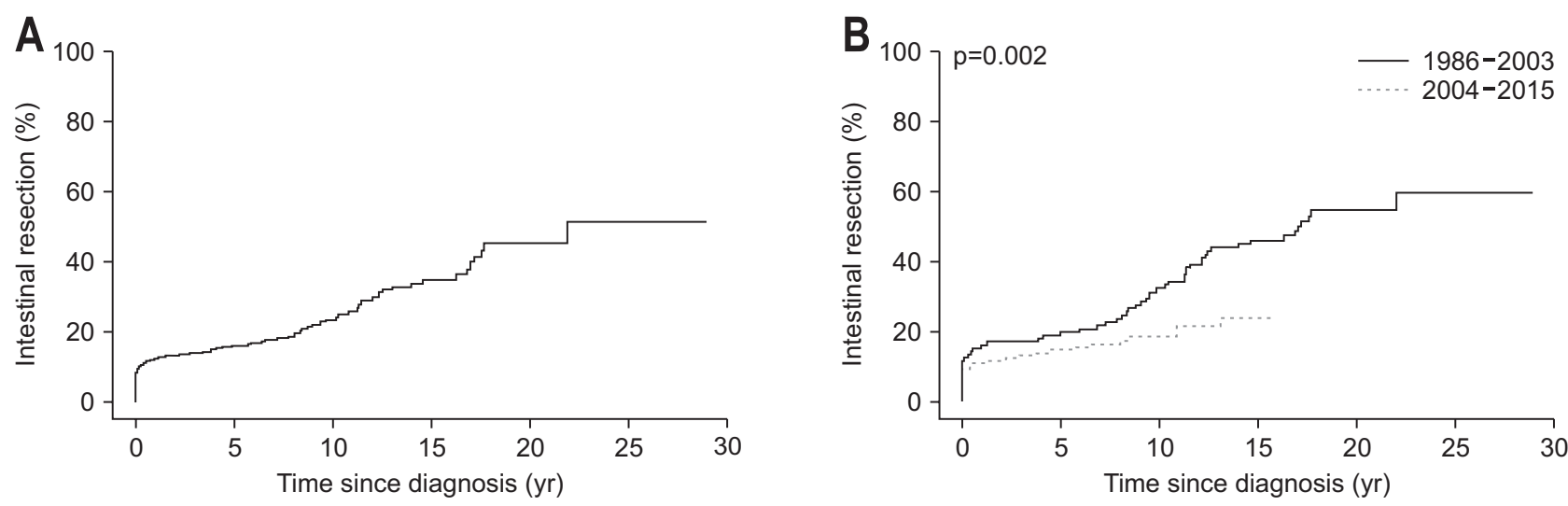

\begin{tabular}{cccccc}
\hline Cumulative risk & $1 \mathrm{yr}$ & $5 \mathrm{yr}$ & $10 \mathrm{yr}$ & $20 \mathrm{yr}$ & $25 \mathrm{yr}$ \\
\hline $1986-2015$ & $12.7 \%$ & $16.5 \%$ & $23.8 \%$ & $45.1 \%$ & $51.2 \%$ \\
\hline
\end{tabular}

\begin{tabular}{cccccc}
\hline Cumulative risk & $1 \mathrm{yr}$ & $5 \mathrm{yr}$ & $10 \mathrm{yr}$ & $20 \mathrm{yr}$ & $25 \mathrm{yr}$ \\
\hline $1986-2003$ & $16.4 \%$ & $20.1 \%$ & $32.5 \%$ & $54.6 \%$ & $59.6 \%$ \\
$2004-2015$ & $11.4 \%$ & $15.1 \%$ & $18.7 \%$ & - & - \\
\hline
\end{tabular}

Fig. 4. Cumulative risk of intestinal resection among patients with Crohn's disease: $(A)$ in the entire cohort and $(B)$ in the two temporal cohorts.
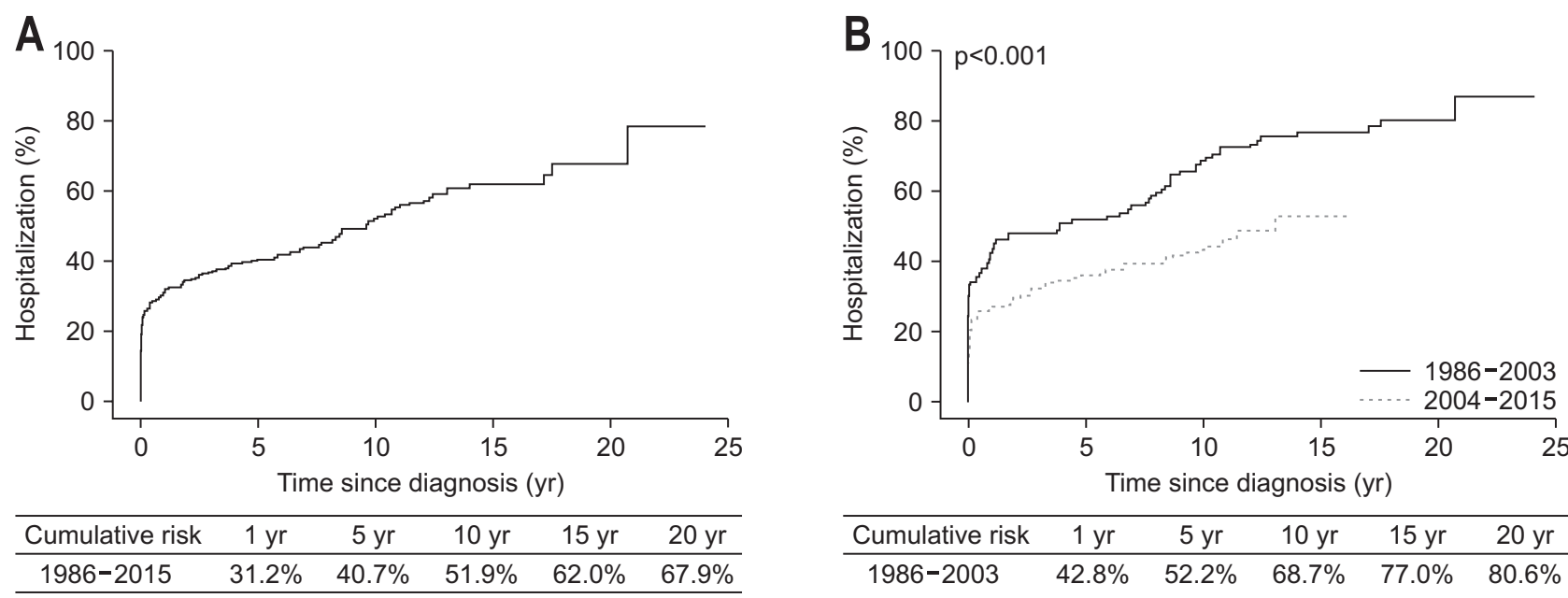

\begin{tabular}{cccccc}
\hline Cumulative risk & $1 \mathrm{yr}$ & $5 \mathrm{yr}$ & $10 \mathrm{yr}$ & $15 \mathrm{yr}$ & $20 \mathrm{yr}$ \\
\hline $1986-2003$ & $42.8 \%$ & $52.2 \%$ & $68.7 \%$ & $77.0 \%$ & $80.6 \%$ \\
$2004-2015$ & $27.0 \%$ & $36.6 \%$ & $43.7 \%$ & $53.1 \%$ & - \\
\hline
\end{tabular}

Fig. 5. Cumulative risk of hospitalization among patients with Crohn's disease: (A) in the entire cohort and (B) in the two temporal cohorts.

resection in 70 patients $(32.4 \%)$. The cumulative probabilities of hospitalization at $1,5,10$, and 20 years after diagnosis were $31.2 \%, 40.7 \%, 51.9 \%$, and $67.9 \%$ (Fig. 5A), respectively, and these probabilities were significantly lower in Cohort 2 than Cohort 1 ( $\mathrm{p}<0.001$ ) (Fig. 5B). Multivariable Cox regression analysis revealed that year of diagnosis $\left(\mathrm{aHR}_{2004-2015}, 0.56\right.$; $95 \% \mathrm{CI}, 0.43$ to 0.75$)$ and disease behavior at diagnosis $\left(\mathrm{aHR}_{\mathrm{B} 2}, 2.19 ; 95 \% \mathrm{CI}, 1.47\right.$ to 3.27 and $\mathrm{aHR}_{\mathrm{B} 3}, 6.02 ; 95 \% \mathrm{CI}, 4.13$ to 8.79 ) were independent predictors of hospitalization (Table 2). When analyzed after excluding 119 patients who were hospitalized within 6 months of diagnosis, the above two factors remained statistically significant (Table 3 ).

\section{Mortality}

Overall, eight patients $(1.9 \%$, five males and three fe- males) died after a median follow-up duration of 79.1 months (range, 17.1 to 306.0 months). Of these eight patients, six patients died of diseases unrelated to $\mathrm{CD}$. The cumulative survival rates at $1,5,10,20$, and 30 years after diagnosis were $100 \%, 99.0 \%, 98.6 \%, 98.6 \%$, and $84.5 \%$, respectively. The standardized mortality ratio among $\mathrm{CD}$ patients was 1.36 (95\% CI, 0.59 to 2.68).

\section{DISCUSSION}

To the best of our knowledge, this was the first population-based study that evaluated the long-term clinical course patients with $\mathrm{CD}$ over 30 years in a non-Caucasian population. One of the intriguing findings of the present study was that the cumulative probability of intestinal re- 
section appeared to be lower in our study (only $45 \%$ at 20 years) than in Western studies. When the comparison was confined to the results of studies conducted in the biologic era, the 5-year cumulative probability of intestinal resection in our study (15.1\% in patients diagnosed in 20042015) was similar to or lower than those in Western studies (19.6\% in Danish patients diagnosed in 2003-2011, ${ }^{31} 17.4 \%$ in Dutch patients diagnosed in $2006-2011,{ }^{26}$ and $22 \%$ in European patients diagnosed in $2010^{23}$ ) although the cumulative probability of anti-TNF use in our study (24.5\%) was similar to or lower than those in Western studies (19\%, $41.2 \%$, and $30 \%$, respectively). For detailed comparisons, see Supplementary Table 1. Considering the high proportion of our patients with poor prognostic factors-i.e., young age at diagnosis (A1 or A2, 90.9\%), ileal involvement (L1 or L3, 90.7\%), and perianal fistula at diagnosis (43.3\%)—compared with that of Western patients, ${ }^{23,26,31}$ it is not clear why our patients showed a low rate of intestinal resection. One possible explanation is that the cultural preferences of Koreans may have partly contributed to lowering the intestinal resection rate. For example, the dictates of Confucianism, which is relatively popular in Korea, influence a reluctance among some patients to undergo intestinal resection, and this might have affected the intestinal resection rate in the short-term. ${ }^{8}$ However, it is difficult to explain the low 20-year cumulative probability of intestinal resection only with cultural preferences because it may be possible to postpone intestinal resection for a short time, but it is impossible to delay it for a long time. Another possibility is that the impact of some prognostic factors on the probability of intestinal resection may be less prominent among Koreans. For example, previous Korean studies failed to show a higher probability of intestinal resection among patients with perianal fistulas than among those without perianal fistulas. ${ }^{32,33}$ Perianal fistula was also not a predictor of intestinal resection in the present study. However, the exact causes of the differences in the intestinal resection rates between the present study and previous Western studies are still unclear. Unrevealed factors, such as genetic and epigenetic differences according to ethnicity, might have contributed to this observation. This issue remains to be further elucidated.

Another notable finding of the current study was that the intestinal resection rate has decreased during the antiTNF era. In our study, the cumulative probability of starting corticosteroids has decreased, whereas the cumulative probabilities of commencing thiopurines and anti-TNF agents have increased over the study period. This evolving pattern of $\mathrm{CD}$ treatment was also observed in Western studies. ${ }^{26,31}$ Moreover, previous Western studies, like our present study, revealed that disease outcomes have been improving in recent years. ${ }^{24-26,31}$ However, we could not demonstrate an association between early use of anti-TNFs and the improvement of disease outcomes. Similarly, previous Western studies could not ascertain the true impact of anti-TNF therapy on the rate of surgery. ${ }^{23,26,34}$ These results suggest that changes in unmeasured confounders, including improved awareness of the disease, introduction of therapeutic guidelines, and continuing medical education for IBD, may have contributed to lowering the rate of intestinal resection over time. ${ }^{35}$ However, further studies are required to explore the causality between the introduction of anti-TNF therapy and the reduced intestinal resection rate because our study, like most previous Western studies, was not designed to address this issue.

Our study had several strengths. First, all inhabitants in our study area were covered by a unified public health insurance system provided by the Korean government, and they had unrestricted access to medical facilities at any time. Therefore, our population-based study included unselected patients representing the entire disease spectrum, and our patients received relatively uniform disease management regulated by the universal reimbursement criteria. Second, our study utilized the strictly defined criteria for diagnosis and classification of $\mathrm{CD}$ and regularly updated clinical information during follow-up. This was a definite advantage over population-based studies using health administrative data. Third, by enrolling patients over 30 years, temporal trends of disease outcomes could be evaluated, particularly according to the introduction of anti-TNF agents.

However, we have to admit that there were a few limitations in the present study. First, data on the CD activity index, occurrence of extraintestinal manifestations, or any changes in smoking habit during follow-up was not collected. Therefore, we could not evaluate the impact of these factors on treatment responses and disease outcomes. Second, it is unclear whether our results can be extrapolated to other Asian populations because there is heterogeneity in the genotypic and phenotypic characteristics of $\mathrm{CD}$ among different Asian populations. ${ }^{5,36,37}$ Therefore, our study results should be validated in other Asian populations. Third, because vedolizumab and ustekinumab were used only in a small number of patients, their real-life effectiveness could not be evaluated.

In conclusion, the results of our population-based study suggest that the long-term prognosis of Korean patients with CD is at least as good as that of Western patients, as indicated by the low rate of intestinal resection. Moreover, the rates of behavioral progression, intestinal resection, and hospitalization have decreased over the past three decades. 


\section{CONFLICTS OF INTEREST}

B.D.Y. has received a research grant from Celltrion and Pfizer Korea; consulting fees from AbbVie Korea, Celltrion, Chong Kun Dang Pharm., Daewoong Pharma., Ferring Korea, Janssen Korea, Kangstem Biotech, LG Chem., Medtronic Korea, Shire Korea, Takeda Korea, IQVIA, and Takeda; speaking fees from AbbVie Korea, Celltrion, Ferring Korea, Janssen Korea, Pfizer Korea, Shire Korea, Takeda Korea, and IQVIA. However, none of these are associated with this study. S.K.Y. received a research grant from Janssen Korea. The other authors have nothing to disclose.

J.P.I. is an editorial board member of the journal but was not involved in the peer reviewer selection, evaluation, or decision process of this article. No other potential conflicts of interest relevant to this article were reported.

\section{ACKNOWLEDGEMENTS}

This work was partially supported by a Korean Health Technology R\&D Project grant from the Korea Health Industry Development Institute to S.K.Y. (A120176), funded by the Ministry of Health \& Welfare, and by a research grant from Janssen Korea. The study sponsors did not participate in the study design, data collection, data analysis, data interpretation, manuscript writing, or decision to submit for publication.

The authors acknowledge Euiyoun Kang (Asan Medical Center, Seoul, Korea) and Eun Ja Youn (Asan Medical Center, Seoul, Korea) for their data abstraction efforts.

This study was presented as a poster at the 15th Congress of European Crohn's and Colitis Organisation (ECCO) in Vienna, Austria, and as an ePoster at Digestive Disease Week 2020.

\section{AUTHOR CONTRIBUTIONS}

Study concept and design: B.D.Y., S.N.H., S.I.S., S.K.Y. Acquisition of data: B.D.Y., S.N.H., S.I.S., J.M.C., K.H.R., H.Y., Y.H.K., K.H.K., S.Y.P., S.K.J., J.H.L., H.P., J.S.K., J.P.I., S.H.K., J.J., J.H.K., S.O.S., Y.K.K., S.H.P., S.K.Y. Statistical analysis and interpretation of data: B.D.Y., Y.J.K., S.H.P., S.K.Y. Drafting of the manuscript: B.D.Y., S.N.H., S.I.S., S.K.Y. Critical revision of the manuscript for important intellectual content: S.K.Y. Study supervision: S.K.Y.

\section{ORCID}

Byong Duk Ye https://orcid.org/0000-0001-6647-6325 Sung Noh Hong https://orcid.org/0000-0002-4140-3717 Seung In Seo https://orcid.org/0000-0003-4417-0135 Ye-Jee Kim https://orcid.org/0000-0002-3307-2970 Jae Myung Cha https://orcid.org/0000-0001-9403-230X Kyoung Hoon Rhee

https://orcid.org/0000-0001-5144-0135

Hyuk Yoon https://orcid.org/0000-0002-2657-0349

Young-Ho Kim https://orcid.org/0000-0003-1803-2513

Kyung Ho Kim https://orcid.org/0000-0002-9607-6258

Sun Yong Park https://orcid.org/0000-0002-8367-2587

Seung Kyu Jeong https://orcid.org/0000-0002-6027-3719

Ji Hyun Lee https://orcid.org/0000-0001-9368-5739

Hyunju Park https://orcid.org/0000-0002-2017-7191

Joo Sung Kim https://orcid.org/0000-0001-6835-4735

Jong Pil Im https://orcid.org/0000-0003-1584-0160

Sung Hoon Kim https://orcid.org/0000-0002-6412-9757

Jisun Jang https://orcid.org/0000-0003-1469-8940

Jeong Hwan Kim https://orcid.org/0000-0002-2503-2688

Seong O Suh https://orcid.org/0000-0003-3727-7815

Young Kyun Kim https://orcid.org/0000-0002-0384-1871

Sang Hyoung Park https://orcid.org/0000-0002-5366-5749

Suk-Kyun Yang https://orcid.org/0000-0003-2772-2575

\section{SUPPLEMENTARY MATERIALS}

Supplementary materials can be accessed at https://doi. org/10.5009/gnl210044.

\section{REFERENCES}

1. Kaplan GG, Ng SC. Understanding and preventing the global increase of inflammatory bowel disease. Gastroenterology 2017;152:313-321.

2. Ananthakrishnan AN, Kaplan GG, Ng SC. Changing global epidemiology of inflammatory bowel diseases: sustaining health care delivery into the 21st century. Clin Gastroenterol Hepatol 2020;18:1252-1260.

3. Kaibullayeva J, Ualiyeva A, Oshibayeva A, Dushpanova A, Marshall JK. Prevalence and patient awareness of inflammatory bowel disease in Kazakhstan: a cross-sectional study. Intest Res 2020;18:430-437.

4. Park SH, Kim YJ, Rhee KH, et al. A 30-year trend analysis in the epidemiology of inflammatory bowel disease in the Songpa-Kangdong district of Seoul, Korea in 1986-2015. J Crohns Colitis 2019;13:1410-1417.

5. Liu JZ, van Sommeren S, Huang H, et al. Association analy- 
ses identify 38 susceptibility loci for inflammatory bowel disease and highlight shared genetic risk across populations. Nat Genet 2015;47:979-986.

6. Hong M, Ye BD, Yang SK, et al. Immunochip meta-analysis of inflammatory bowel disease identifies three novel loci and four novel associations in previously reported loci. J Crohns Colitis 2018;12:730-741.

7. Yang SK, Yun S, Kim JH, et al. Epidemiology of inflammatory bowel disease in the Songpa-Kangdong district, Seoul, Korea, 1986-2005: a KASID study. Inflamm Bowel Dis 2008;14:542-549.

8. Ye BD, Yang SK, Cho YK, et al. Clinical features and longterm prognosis of Crohn's disease in Korea. Scand J Gastroenterol 2010;45:1178-1185.

9. Zeng Z, Zhu Z, Yang Y, et al. Incidence and clinical characteristics of inflammatory bowel disease in a developed region of Guangdong Province, China: a prospective populationbased study. J Gastroenterol Hepatol 2013;28:1148-1153.

10. Park SH, Yang SK, Park SK, et al. Long-term prognosis of Crohn's disease and its temporal change between 1981 and 2012: a hospital-based cohort study from Korea. Inflamm Bowel Dis 2014;20:488-494.

11. Yen HH, Weng MT, Tung CC, et al. Epidemiological trend in inflammatory bowel disease in Taiwan from 2001 to 2015: a nationwide populationbased study. Intest Res 2019;17:54-62.

12. Yang SK. How does the epidemiology of inflammatory bowel disease differ between east and west? A Korean perspective. Inflamm Intest Dis 2017;2:95-101.

13. Oriuchi T, Hiwatashi N, Kinouchi Y, et al. Clinical course and longterm prognosis of Japanese patients with Crohn's disease: predictive factors, rates of operation, and mortality. J Gastroenterol 2003;38:942-953.

14. Siddique I, Alazmi W, Al-Ali J, et al. Clinical epidemiology of Crohn's disease in Arabs based on the Montreal classification. Inflamm Bowel Dis 2012;18:1689-1697.

15. Goel A, Dutta AK, Pulimood AB, Eapen A, Chacko A. Clinical profile and predictors of disease behavior and surgery in Indian patients with Crohn's disease. Indian J Gastroenterol 2013;32:184-189.

16. Aljebreen AM, Alharbi OR, Azzam NA, Almalki AS, Alswat KA, Almadi MA. Clinical epidemiology and phenotypic characteristics of Crohn's disease in the central region of Saudi Arabia. Saudi J Gastroenterol 2014;20:162-169.

17. Kim HJ, Hann HJ, Hong SN, et al. Incidence and natural course of inflammatory bowel disease in Korea, 2006-2012: a nationwide population-based study. Inflamm Bowel Dis 2015;21:623-630

18. Ng SC, Zeng Z, Niewiadomski O, et al. Early course of inflammatory bowel disease in a population-based inception cohort study from 8 countries in Asia and Australia. Gastroenterology 2016;150:86-95.
19. Ng SC, Leung WK, Shi HY, et al. Epidemiology of inflammatory bowel disease from 1981 to 2014: results from a territory-wide population-based registry in Hong Kong. Inflamm Bowel Dis 2016;22:1954-1960.

20. Loftus EV Jr, Silverstein MD, Sandborn WJ, Tremaine WJ, Harmsen WS, Zinsmeister AR. Crohn's disease in Olmsted County, Minnesota, 1940-1993: incidence, prevalence, and survival. Gastroenterology 1998;114:1161-1168.

21. Lee YJ, Yang SK, Byeon JS, et al. Analysis of colonoscopic findings in the differential diagnosis between intestinal tuberculosis and Crohn's disease. Endoscopy 2006;38:592-597.

22. Silverberg MS, Satsangi J, Ahmad T, et al. Toward an integrated clinical, molecular and serological classification of inflammatory bowel disease: report of a Working Party of the 2005 Montreal World Congress of Gastroenterology. Can J Gastroenterol 2005;19 Suppl A:5A-36A.

23. Burisch J, Kiudelis G, Kupcinskas L, et al. Natural disease course of Crohn's disease during the first 5 years after diagnosis in a European population-based inception cohort: an Epi-IBD study. Gut 2019;68:423-433.

24. Ramadas AV, Gunesh S, Thomas GA, Williams GT, Hawthorne AB. Natural history of Crohn's disease in a population-based cohort from Cardiff (1986-2003): a study of changes in medical treatment and surgical resection rates. Gut 2010;59:1200-1206

25. Lakatos PL, Golovics PA, David G, et al. Has there been a change in the natural history of Crohn's disease? Surgical rates and medical management in a population-based inception cohort from Western Hungary between 1977-2009. Am J Gastroenterol 2012;107:579-588.

26. Jeuring SF, van den Heuvel TR, Liu LY, et al. Improvements in the long-term outcome of Crohn's disease over the past two decades and the relation to changes in medical management: results from the population-based IBDSL cohort. Am J Gastroenterol 2017;112:325-336.

27. Ooi CJ, Hilmi I, Banerjee R, et al. Best practices on immunomodulators and biologic agents for ulcerative colitis and Crohn's disease in Asia. Intest Res 2019;17:285-310.

28. Hanauer SB. Crohn's disease: step up or top down therapy. Best Pract Res Clin Gastroenterol 2003;17:131-137.

29. Wolfe RA. The standardized mortality ratio revisited: improvements, innovations, and limitations. Am J Kidney Dis 1994;24:290-297.

30. Statistics Korea. Number of deaths and death rate by cause of death (103 items)/sex/age (5 years old) [Internet]. Daejeon: Korean Statistical Information Service; c2020 [cited 2020 Apr 14]. Available from: https://kosis.kr/statHtml/statHtml. do?orgId=101\&tblId=DT_1B34E01\&conn_path=I2.

31. Rungoe C, Langholz E, Andersson M, et al. Changes in medical treatment and surgery rates in inflammatory bowel disease: a nationwide cohort study 1979-2011. Gut 
2014;63:1607-1616.

32. Yoon JY, Cheon JH, Park SJ, Kim TI, Kim WH. Effects of perianal involvement on clinical outcomes in Crohn's disease over 10 years. Gut Liver 2018;12:297-305.

33. Chun J, Im JP, Kim JW, et al. Association of perianal fistulas with clinical features and prognosis of Crohn's disease in Korea: results from the CONNECT study. Gut Liver 2018;12:544-554.

34. Murthy SK, Begum J, Benchimol EI, et al. Introduction of anti-TNF therapy has not yielded expected declines in hospitalisation and intestinal resection rates in inflammatory bowel diseases: a population-based interrupted time series study. Gut 2020;69:274-282.

35. Frolkis AD, Dykeman J, Negrón ME, et al. Risk of surgery for inflammatory bowel diseases has decreased over time: a systematic review and meta-analysis of population-based studies. Gastroenterology 2013;145:996-1006.

36. Thia KT, Loftus EV Jr, Sandborn WJ, Yang SK. An update on the epidemiology of inflammatory bowel disease in Asia. Am J Gastroenterol 2008;103:3167-3182.

37. Ng WK, Wong SH, Ng SC. Changing epidemiological trends of inflammatory bowel disease in Asia. Intest Res 2016;14:111-119. 